\title{
Preparation and Characterization of Metal Soaps of Cocos Nucifera Seed Oil
}

\author{
*11OSSAI EK \\ Department of Chemistry, Delta State University, Faculty of Science, Abraka, Nigeria. \\ Email address: ossaiek@yahoo.com
}

KEY WORDS: Cocos nucifera seed oil, metal soaps, corrosion inhibition, foam stability

\begin{abstract}
ABSRACT: This study investigated the extraction of Cocos Nucifera seed oil (CSO) from Cocos nucifera seed using aqueous processing and the production of metal soaps from the oil and their characterization in terms of colour, $\mathrm{pH}$, free caustic alkalinity, foaming power, foam stability, and corrosion inhibition test. The metal soaps of the oil produced by metathesis were soaps of nickel, calcium, barium, zinc, iron and magnesium. The results of tests of the metal soaps showed that $\mathrm{Ni}-\mathrm{CSO}$ was greenish in colour, $\mathrm{Zn}-\mathrm{CSO}, \mathrm{Mg}-\mathrm{CSO}, \mathrm{Ba}-\mathrm{CSO}$ and $\mathrm{Ca}-\mathrm{CSO}$ were white and Fe-CSO had a dark-brown colour. The $\mathrm{pH}$ of the metal soaps varied between 6.5 to 8.2. The free caustic alkalinity was low and varied between $0.30 \%$ to $0.43 \%$. Foam stability was in the order Fe-CSO 0.80, Ca-CSO 0.81, Zn-CSO 0.86, Ni-CSO 0.90, Mg-CSO 0.92 and Ba-CSO 0.93. For corrosion inhibition test Ni-CSO at $100 \mathrm{mg} / \mathrm{L}, \mathrm{Ca}-\mathrm{CSO}$ at $60 \mathrm{mg} / \mathrm{L}, \mathrm{Mg}-\mathrm{CSO}, \mathrm{Ba}-\mathrm{CSO}$ and $\mathrm{Fe}-\mathrm{CSO}$ at $40 \mathrm{mg} / \mathrm{L}$ inhibited tiger head razor blade corrosion while the other concentrations of the metal soaps showed varied degrees of corrosion. ( ) JASEM
\end{abstract}

\section{http://dx.doi.org/10.4314/jasem.v18 i2.29}

Introduction: Cocos nucifera (coconut palm) is a member of the family Arecaceae (palm family). It is the only accepted species in the genus Cocos. The term coconut can refer to the entire coconut palm, the seed, or the fruit, which botanically is a drupe, not a nut. The term is derived from $16^{\text {th }}$ century Portuguese and Spanish coco meaning "head" or "shell" from the three indentations on the coconut shell that resemble facial features. Found throughout the tropic and subtropic area, the coconut is known for its great versatility as seen in the many uses of its different parts. Coconuts are part of the daily diets of many people. Coconuts are different form other fruits because they contain a large quantity of "water" and when immature they are known as tender-nuts or jelly-nuts and may be harvested for drinking when mature, they still contain some water and can be used as seed nuts or processed to give oil from the kernel (fresh), charcoal from the hard shell and coir from the fibrous husk. Coconut has edible coconut fresh when dried the coconut is called copra. The oil and milk derived from it are commonly used in cooking and frying, coconut oil is also widely used in soaps and cosmetics. The clear liquid coconut water within is a refreshing drink (Wikipedia, 2014). Cocos nucifera seed oil is used as pomade by many Nigerians. Cocos nucifera $\mathrm{L}$. is a tree that is cultivated for its multiple utilities mainly for its nutritional and medicinal values. It is the unique source of various natural products for the development of medicines and industrial products (DebMandel and Mandel, 2011).
Soaps are sodium or potassium salts of fatty acids. For thousands of years soap was prepared by heating animal fat or oil with wood ashes. Wood ashes contain potassium carbonate and sodium carbonate which make the solution basic. The modern commercial method of making soap involves boiling fats or oils in aqueous sodium hydroxide or potassium hydroxide and adding sodium chloride or potassium chloride to precipitate the soaps respectively. The soap is then dried and pressed into bars. Perfumes can be added for scented soaps, dyes can be added for coloured soaps, sand can be added for scouring soaps, and air can be blown into the soaps to make if float. Soap has a nonpolar hydrocarbon end and polar carboxylate ion end. These form micelle which is a spherical cluster as they do not dissolve in aqueous solution. The nonpolar ends attach themselves to dirt or oil which dissolves it and they are carried away. In addition, soaps lower the surface tension of water. That is why soap solution feels slippery. Lowering the surface tension enables the soap to penetrate the fibres of a fabric thus enhancing its cleansing ability (Bruice, 1995).

Seed oils are important sources of nutritional oils, industrial and pharmaceutical raw materials (Oderinde et al, 2009) and current emphasis in sustainable development has made it imperative to reach for industrial raw materials from renewable sources. Oils are at the centre of this search as useful products and industrial materials have been produced 
from them. One of such materials is metal carboxylates otherwise called metal soaps. Metal soaps have been classified as alkaline-earth or heavymetal long chain carboxylates (Barth, 1982), which are insoluble in water but soluble in non-aqueous solvents. They have the general formula $\left(\mathrm{KCO}_{2}\right)_{2} \mathrm{M}$ where $\mathrm{M}$ is a metal such as $\mathrm{Zn}, \mathrm{Cd}, \mathrm{Pb}, \mathrm{Ba}, \mathrm{Ca}, \mathrm{Co}$, $\mathrm{Cu}, \mathrm{Al}, \mathrm{Fe}$, e.t.c. and $\mathrm{R}$ is a linear or branched alkyl group (Folarin et al., 2011). Metal soaps are manufactured by using one of the following processes: double decomposition, direct reaction of carboxylic acid with metal oxides, hydroxides and carbonates and direct reaction of metals with molten fatty acid (Gonen et al., 2005). These reactions are usually carried out in an aqueous medium for alkaline and alkaline - earth soaps or in an organic medium, such as alcohol or benzene, for metallic soaps (Upadhyaya and Sharma, 1997; Akanni et al., 1992). Metal carboxylates have played an important role in the development of poly(vinyl chloride) (PVC) as an important commercial polymer (Owen and Msayib, 1989; Bucalogulu et al., 2007). Soaps, alkaline and alkaline - earth as well as metallic soaps are employed in various fields (Poulenat et al., 2004). These metal soaps have many industrial uses lead, manganese, cobalt and zinc soaps are used in paints to accelerate drying while copper soaps exhibits fungicidal properties. Calcium and magnesium soaps are used as corrosion inhibitors in non - aqueous media (Salvager, 2002). Silver carboxylates are used as source of silver in thermographic and photothermographic materials (Bienremans, 2004) while some other soaps have find application in greases, cosmetics and textiles (Egbuchunam et al., 2005, Folarin and Enikanoselu, 2010). Some synthesis of metal nanoparticles, have incorporated some fatty acids to prevent the aggregation of the nanoparticles, some of these metal soaps can function as precursors for generating fatty acids that could be useful in the field of nanochemistry (Essien et al., 2012, Ekuyana et al., 2004). Most of the works in literature discussed soaps from fatty acids and some oils but works on metal soaps of Cocos nucifera seed oil are very scanty. The objectives of this study are to extracted Cocos nucifera seed oil from the seed, prepare metal soaps from it and characterize the soaps in terms of colour, $\mathrm{pH}$, the free caustic alkalinity, foaming power and foam stability, and corrosion inhibition test.

\section{MATERIALS AND METHOD}

Coconut fruit was obtained from Abraka market, Delta State, Nigeria. $\mathrm{Ca}\left(\mathrm{NO}_{3}\right)_{2} \cdot 2 \mathrm{H}_{2} \mathrm{O}, \mathrm{MgSO}_{4} \cdot 7 \mathrm{H}_{2} \mathrm{O}$, $\mathrm{Ba}\left(\mathrm{NO}_{3}\right)_{2}, \quad \mathrm{NiSO}_{4} \cdot 6 \mathrm{H}_{2} \mathrm{O}, \mathrm{FeSO}_{4}$ and $\mathrm{Zn}\left(\mathrm{NO}_{3}\right)_{2}$, petroleum spirit, ethanol, sulphuric acid and hydrochloric acid were obtained from $\mathrm{BDH}$
Chemicals, England as analytical grade chemicals and used as received.

Extraction of Cocos nucifera seed oil (CSO): Cocos nucifera seed oil was extracted by aqueous processing where water was used to extract the oil. The flesh of the coconut is separated from the shell, cut into several chunks, grated using a ford grater, water was added and then filtered using a sieve. The milky liquid was boiled for a period of time almost till the water was dried up in the pot using a gas cooker as a source of heat but as it boiled oil separated from the water. The oil was then skimmed from the surface and collected. Determination of saponification value was done using the method of Pearson (1976).

Preparation of metal soaps: The metallic soap of CSO was prepared by metathesis in aqueous alcoholic solution as described by Burrows et al (1981). $9.2 \mathrm{~g}$ of coconut oil was dissolved in $50 \mathrm{ml}$ of hot ethanol followed by treatment with $20 \mathrm{ml}$ of $20 \%$ (w/v) sodium hydroxide solution. To this mixture $30 \%(\mathrm{w} / \mathrm{v})$ solution of the appropriate metal was slowly added with continuous stirring. The precipitated metal soaps were filtered off washed with hot water and air dried. The CSO soaps were prepared using these salts: $\mathrm{Ca}\left(\mathrm{NO}_{3}\right)_{2} \cdot 2 \mathrm{H}_{2} \mathrm{O}$, $\mathrm{MgSO}_{4} \cdot 7 \mathrm{H}_{2} \mathrm{O}, \mathrm{NiSO}_{4} \cdot 6 \mathrm{H}_{2} \mathrm{O}, \mathrm{Ba}\left(\mathrm{NO}_{3}\right)_{2}, \mathrm{Zn}\left(\mathrm{NO}_{3}\right)_{2}$ and $\mathrm{FeSO}_{4}$. The colours of the metal soaps were noted.

Determination of free caustic alkalinity: Five grams of soap was dissolved in $100 \mathrm{ml}$ hot neutralized ethanol in a $250 \mathrm{ml}$ conical flask and $20 \mathrm{ml}$ of $10 \%$ barium chloride was added. A pink colour of the solution indicated the presence of a free caustic alkali. The solution was titrated immediately with $0.1 \mathrm{~N} \mathrm{HCl}$ until the colour disappeared (Milwidsky and Gabriel, 1994). The free caustic alkali was calculated by:

$\%$ free caustic alkalinity $=(0.4 \mathrm{~V}) / \mathrm{W}$, where $\mathrm{V}=$ colour of $0.1 \mathrm{~N} \mathrm{HCl}(\mathrm{ml}), \mathrm{W}=$ weight of sample $(\mathrm{g})$.

Foaming Power and foam stability: $200 \mathrm{ml}$ of $0.1 \%$ soap suspension was poured into a $500 \mathrm{ml}$ measuring cylinder. Foam was whipped up with 30 vigorous strokes of a perforated plunger. The foam volume was noted after $30 \mathrm{~s}$ and $5.5 \mathrm{~min}$. The foam stability was expressed as a ratio of the foam volume at 5.5 min to that at $30 \mathrm{~s}\left(\mathrm{~V}_{5} / \mathrm{V}_{\mathrm{o}}\right)$ (Awang et al., 2001). This method was used for the various metal soaps and the values were recorded.

pH test: $2 \mathrm{~g}$ of soaps were added into $20 \mathrm{ml}$ distilled water and shaken and the soap suspensions were allowed to stay for at least 12 hours before the $\mathrm{pH}$ meter was inserted into a beaker containing the 
various soap suspensions, and the readings were recorded (Avang et al., 2001).

Corrosion inhibition test: Various concentrations (20, $40,60,80,100,120,150 \mathrm{mg} / \mathrm{L})$ of the metal soaps were prepared by suspending the soap in deionized water. Flasks were filled with the soap suspensions; tiger head razor blades were weighed and measured into each soap suspension then left for the lapse of 24 hours. The blades were brought out cleaned and weighed.

The percentage weight loss (\% WL) was calculated using the relationship:

$\% \mathrm{WL}=\underline{\mathrm{W}}_{1} \frac{-\mathrm{W}_{2}}{\mathrm{~W}_{2}} \times 100$

Where $\mathrm{W}_{1}=$ the original weight before immersion $\mathrm{W}_{2}=$ is the weight after immersion

\section{RESULTS AND DISCUSSION}

The saponification of value of the oil extracted from Cocos nucifera was $249.65 \mathrm{mg} / \mathrm{KOH} / \mathrm{g}$ and the literature value was 246 - $260 \mathrm{mg} / \mathrm{KOH} / \mathrm{g}$. This showed that the extracted oil was fresh. The result of colour and $\mathrm{pH}$ are given in Table 1 below.

The $\mathrm{pH}$ of the metal soaps varied between 6.7 - 8.2. $\mathrm{Ba}-\mathrm{CSO}, \mathrm{Fe}-\mathrm{CSO}$ and Ni-CSO were acidic while $\mathrm{Zn}$ $\mathrm{CSO}, \mathrm{Ca}-\mathrm{CSO}$ and $\mathrm{Mg}-\mathrm{CSO}$ were basic. The soaps of the alkaline-earth metals were white while those of transition metals were coloured expect zinc. Zinc was not a typical transition metal that was why the salt was white. All the d orbitals are filled in zinc. The values obtained by titrating the metal soaps with $0.1 \mathrm{~N} \mathrm{HCl}$ are given below and the $\%$ free caustic alkalinity which was obtained from the relationship : $(0.4 \mathrm{~V}) / \mathrm{W}$ where $\mathrm{V}$ is the value of acid used and $\mathrm{W}$ is the weight of soap. Table 2 below shows the free caustic alkalinity of the metal soaps.

The $\%$ free caustic alkalinity varied between $0.30 \%$ to $0.43 \%$. Fe-CSO had the highest value of $\%$ free caustic alkalinity while $\mathrm{Ca}-\mathrm{CSO}$ has the lowest value. The values indicated that there was still some alkalinity left in the soaps.

Foaming power and foam stability: The Table 3 below indicates the values obtained for the volume of the foam at $30 \mathrm{~s}$ and $5.5 \mathrm{~min}$ and the calculated foam stabilities respectively. The foam stability varied between $0.80-0.93$. Fe-CSO had the lowest foam stability and Ba-CSO had the highest value. The higher the foam stability the more the ability of the soap to have detergency property. The metal soaps have poor detergency properties due to their insolubility in water. The foam power and foam stability of metal soaps may be useful in their application as foam fire extinguishers. The metal $*^{l}$ OSSAI, E.K. soaps are soluble in sodium alkyl benzenesulphonate or sodium lauryl sulphate and the products are good fire extinguishers. Fire need fuel, oxygen and heat in order to burn so the fire extinguisher is designed to remove one of these elements. Foam floats on inflammable liquids to tame the fire and help prevent reflash. Soluble metal soap forms soapy foam that suppresses any vapour and steam like potassium ethanoate based commercial class $\mathrm{K}$ fire extinguisher. Corrosion Inhibition Test: The values obtained before (BF) and after (AF) immersion of metal into the various metal soap suspensions are given in the Table 4 below.

The Table 5 below indicates the weight loss (WL) and percentage weight loss $(\% \mathrm{WL})$ of metal after immersion in soaps at various concentrations. For the corrosion inhibition test, the percentage weight loss of the tiger head razor blade indicated the inhibition characteristics. The lower the percentage weight loss the more the corrosion inhibition. Mg-CSO had the highest weight loss $(9.09 \%)$, and $\mathrm{Zn}-\mathrm{CSO}$ had the lowest $(2.17 \%)$. Mg-CSO at $40 \mathrm{mg} / \mathrm{L}$ had inhibition of corrosion. For Ca-CSO there was inhibition of corrosion at concentration of $60 \mathrm{mg} / \mathrm{L}$, for $\mathrm{Ni}-\mathrm{CSO}$ there was inhibition of corrosion at $100 \mathrm{mg} / \mathrm{L}$, for $\mathrm{Mg}-\mathrm{CSO}, \mathrm{Ba}-\mathrm{CSO}$ and $\mathrm{Fe}-\mathrm{CSO}$ there was inhibition of corrosion at $40 \mathrm{mg} / \mathrm{L}$. For $\mathrm{Zn}-\mathrm{CSO}$ there was some inhibition of corrosion at varying degrees at the different concentrations and the weight loss of the tiger head razor blade varied between $2.17-6.82 \%$. At other concentrations of the other metal soaps the razor blade showed varying degrees of \% weight loss. Inhibition of corrosion by some of the metal soaps at certain concentrations at aqueous medium is of great value for iron protection.

Conclusion: Metal soaps from CSO can be employed as grease, paint additives, stabilizes for PVC and useful at particular concentration for inhibition of corrosion in metals. Mg-CSO, Ba - CSO, Fe-CSO at $40 \mathrm{mg} / \mathrm{L}$ showed inhibition of corrosion of tiger head razor blade at aqueous medium, while $\mathrm{Ca}-\mathrm{CSO}$ at 60 $\mathrm{mg} / \mathrm{L}$ and $\mathrm{Ni}-\mathrm{CSO}$ at $100 \mathrm{mg} / \mathrm{L}$ showed inhibition of corrosion of tiger head razor blade. $\mathrm{Ca}-\mathrm{CSO}, \mathrm{Mg}-$ $\mathrm{CSO}, \mathrm{Ba}-\mathrm{CSO}$ and $\mathrm{Zn}-\mathrm{CSO}$ being white can be useful in white paints as pigments and paint driers, $\mathrm{Ni}-\mathrm{CSO}$ can be useful in green paints and Fe-CSO can be useful in dark-brown paints both as pigments and as paint driers. The metal soaps may have application as plasticisers and thermal stabilisers in poly(vinyl chloride) (PVC) and natural rubber compounds. The pHs of the soaps were within the range (6.5-9.2) allowed for potable water by World Health Organization (WHO, 2011) apart from BaCSO which is slightly lower so they do not constitute danger to the ecosystem with regard to $\mathrm{pH}$. Apart 
from Ni the other metals used for soap preparation are essential metals so they environmentally friendly.

Table 1: Colour and $\mathrm{pH}$ of metal soaps

\begin{tabular}{cll}
\hline Metal Soap & Colour & $\mathrm{pH}$ \\
\hline Ca-CSO & White & 7.7 \\
Ni-CSO & Green & 6.8 \\
Mg-CSO & White & 8.2 \\
Fe-CSO & Dark-brown & 6.5 \\
Ba-CSO & White & 6.3 \\
Zn-CSO & White & 7.4 \\
\hline
\end{tabular}

Acknowledgement: The author is grateful to Okuchi I. of the Department of Chemistry, Delta State

University, Abraka for her assistance in this study.

Table 2: Free Caustic Alkalinity

\begin{tabular}{llll}
\hline Metal & $\begin{array}{l}\text { Final Reading } \\
\text { Soap }\end{array}$ & $\begin{array}{l}\text { Initial Reading } \\
(\mathrm{ml})\end{array}$ & $\begin{array}{l}\text { \% Free Caustic } \\
\text { Alkalinity }\end{array}$ \\
Ca-CSO & 3.70 & 0.00 & 0.30 \\
Ni-CSO & 4.90 & 0.00 & 0.39 \\
Mg-CSO & 4.20 & 0.00 & 0.34 \\
Fe-CSO & 5.40 & 0.00 & 0.43 \\
Ba-CSO & 4.60 & 0.00 & 0.37 \\
Zn-CSO & 3.90 & 0.00 & 0.31 \\
\hline
\end{tabular}

Table 3: Volume (ml) of foam after $30 \mathrm{~s}$ and $5.5 \mathrm{~min}$ and calculated foam stabilities of soaps

\begin{tabular}{llll}
\hline Metal Soap & $\begin{array}{l}\text { Volume } \\
(\mathbf{m l}) \mathbf{3 0} \mathbf{~ s}\end{array}$ & $\begin{array}{l}\text { Volume } \\
(\mathbf{m l}) \mathbf{5 . 5} \mathbf{~ m i n}\end{array}$ & $\mathbf{F s}=\mathbf{V s} / \mathbf{V o}$ \\
\hline $\mathrm{Ca}-\mathrm{CSO}$ & 260 & 210 & 0.81 \\
$\mathrm{Ni}-\mathrm{CSO}$ & 280 & 250 & 0.90 \\
$\mathrm{Mg}-\mathrm{CSO}$ & 120 & 110 & 0.92 \\
$\mathrm{Fe}-\mathrm{CSO}$ & 150 & 120 & 0.80 \\
$\mathrm{Ba}-\mathrm{CSO}$ & 105 & 98 & 0.93 \\
$\mathrm{Zn}-\mathrm{CSO}$ & 140 & 120 & 0.86 \\
\hline
\end{tabular}

Table 4: Weight of metal before (BF) and after (AF) immersion in soap solutions.

\begin{tabular}{|c|c|c|c|c|c|c|c|c|c|c|c|c|}
\hline \multirow{2}{*}{$\begin{array}{l}\text { Conc. } \\
\text { (mg/l) }\end{array}$} & \multicolumn{2}{|c|}{ Ca - CSO } & \multicolumn{2}{|c|}{$\mathrm{Ni}$ - CSO } & \multicolumn{2}{|c|}{ Mg - CSO } & \multicolumn{2}{|c|}{ Fe-CSO } & \multicolumn{2}{|c|}{ Ba - CSO } & \multicolumn{2}{|c|}{ Zn - CSO } \\
\hline & $\mathbf{B F}$ & $\mathbf{A F}$ & $\mathbf{B F}$ & $\mathbf{A F}$ & BF & $\mathbf{A F}$ & $\mathbf{B F}$ & $\mathbf{A F}$ & BF & $\mathbf{A F}$ & $\mathbf{B F}$ & $\mathbf{A F}$ \\
\hline 20 & 0.44 & 0.42 & 0.41 & 0.39 & 0.43 & 0.40 & 0.44 & 0.42 & 0.43 & 0.42 & 0.44 & 0.42 \\
\hline 40 & 0.44 & 0.42 & 0.43 & 0.42 & 0.43 & 0.43 & 0.42 & 0.42 & 0.43 & 0.43 & 0.46 & 0.45 \\
\hline 60 & 0.43 & 0.43 & 0.45 & 0.43 & 0.44 & 0.42 & 0.44 & 0.41 & 0.44 & 0.43 & 0.41 & 0.40 \\
\hline 80 & 0.43 & 0.42 & 0.44 & 0.43 & 0.43 & 0.41 & 0.44 & 0.43 & 0.44 & 0.41 & 0.44 & 0.41 \\
\hline 100 & 0.43 & 0.41 & 0.44 & 0.44 & 0.44 & 0.41 & 0.44 & 0.42 & 0.43 & 0.41 & 0.44 & 0.42 \\
\hline 120 & 0.44 & 0.42 & 0.43 & 0.31 & 0.44 & 0.41 & 0.43 & 0.41 & 0.42 & 0.39 & 0.44 & 0.42 \\
\hline 150 & 0.44 & 0.41 & 0.44 & 0.41 & 0.44 & 0.40 & 0.43 & 0.40 & 0.44 & 0.41 & 0.44 & 0.42 \\
\hline
\end{tabular}

Table 5: The weight loss (WL) and percentage weight loss (\% WL) of metal after immersion in soaps at various concentrations

\begin{tabular}{|c|c|c|c|c|c|c|c|c|c|c|c|c|}
\hline \multirow{2}{*}{$\begin{array}{c}\text { Conc. } \\
\text { (mg/L) }\end{array}$} & \multicolumn{2}{|c|}{ Ca-CSO } & \multicolumn{2}{|c|}{$\mathrm{Ni}-\mathrm{CSO}$} & \multicolumn{2}{|c|}{ Mg-CSO } & \multicolumn{2}{|c|}{ Fe-CSO } & \multicolumn{2}{|c|}{ Ba-CSO } & \multicolumn{2}{|c|}{ Zn-CSO } \\
\hline & WL & $\% \mathrm{WL}$ & WL & $\% \mathrm{WL}$ & WL & $\% \mathrm{WL}$ & WL & $\% \mathrm{WL}$ & WL & $\% \mathrm{WL}$ & WL & $\% \mathrm{WL}$ \\
\hline 20 & 0.02 & 4.45 & 0.02 & 4.88 & 0.03 & 6.98 & 0.02 & 4.55 & 0.01 & 2.33 & 0.02 & 4.55 \\
\hline 40 & 0.02 & 4.45 & 0.01 & 2.33 & 0.00 & 0.00 & 0.00 & 0.00 & 0.00 & 0.00 & 0.01 & 2.17 \\
\hline 60 & 0.00 & 0.00 & 0.02 & 4.40 & 0.02 & 4.55 & 0.03 & 6.82 & 0.02 & 2.27 & 0.01 & 2.27 \\
\hline 80 & 0.01 & 2.33 & 0.01 & 2.27 & 0.02 & 4.65 & 0.01 & 2.27 & 0.02 & 6.82 & 0.03 & 6.82 \\
\hline 100 & 0.02 & 4.65 & 0.00 & 0.00 & 0.03 & 6.82 & 0.04 & 4.55 & 0.03 & 4.65 & 0.02 & 4.55 \\
\hline 120 & 0.02 & 4.55 & 8.80 & 0.02 & 0.03 & 6.82 & 0.02 & 4.65 & 0.03 & 7.14 & 0.02 & 4.55 \\
\hline 150 & 0.03 & 6.82 & 6.82 & 0.03 & 0.04 & 9.09 & 0.03 & 6.98 & 0.04 & 6.82 & 0.02 & 4.55 \\
\hline
\end{tabular}

\section{REFERENCES}

Akanni, S. M; Okah, E. K; Burrows, H. D; Ellis, H. A. (1992). The valent thermal behaviour of divalent and valent metal soaps, a review, Thermochim. Acta. 208: $1-41$.

Bacalogulu, R; Fisch, M. (1994). Degradation and stabilization of poly(vinyl chloride) 11. Kinetics of the thermal degradation of poly (vinyl chloride). Polym. Degrad. Stab. 45: 325 - 333.
Barth, T.F.W. (1982). Soaps in Mc Graw - Hall Encyclopedia of Science and Technology, Mc Graw - Hill Inc. USA, 6(9): 1922 - 1927.

Biennemans, K; Van Deun, R; Thijs, B; Vanwelkenhuysen, I; Geneus, I. (2004).

Structure and mesomorphism of silver alkanoates.

Chem. Mater. 16:2021 - 2027. 
Bruice, P. Y. (1995). Organic Chemistry, Prentice Hall International Inc. Eaglewood Cliff, New Jersey, pp 736.

Burrows, H. D; Ellis, H. A; Akanni, M.S. (1981). Proceeding of the second European symposium on thermal analysis (Dallimore D. Ed.) Heydes, London.

DelMandel, M; Mandel, S. (2011). Coconut (Cocos nucifera $\mathrm{L}$. Arecacaeae) in health promotion and disease prevention, Asian Pacific Journal of Tropical Medicine, 241 - 247.

Egbuchunam T. O; Okieimen P. E; Aigbodion A. I. (2005). Studies in the thermal stability of metal soaps of rubber seed oil, Tech. J. 1: 18-23.

Egbuchunam, T. O; Balkose, D; Okieimen, F. E. (2007). Structure and thermal behaviour of polyvalent metal soaps of rubber seed oil, J. Chem. Soc.Nigeria, 32:107 - 116.

Folarin, O. M; Eromosele, I. C; Eromosele, C. O. (2011). Relative thermal stability soaps of Ximenia Americana and Balanites aegyptiaca used oils, Sci. Res. Essays, 6:1922.

Gonen, M., Balkose, D., Inal, F., Ulku, S. (2005). Zinc stearate production by precipitation and fusion processes, Ind. Eng. Chem. Res. 14(6): 1627 - 1633.
Odemide, R. A; Ajayi, I. A; Ademuji, A. (2009). Characterization of seed and seed oil of Hura crepitans and kinetics of degradation of the oil during heating, EJAFChe, $201-208$.

Owen, E. D; Msayib, K. J. (1989). Catalyzed degradation of poly(vinyl chloride) III Zinc (II) chloride catalysis, J. Polym. Sci. Polym. Chem. A27:399 - 408 .

Pearson, D. (1976). The chemical analysis of foods, 7th ed, Churchill Livingstone, London.

Poulenat, G; Sentenac, C; Moulongui, Z. (2004). Double decomposition reaction for the production of alkaline and alkaline - earth oleic acid soaps under salting out conditions. Ind. Eng. Chem. Res. 43(7):1574 - 1579.

Upadhyaya, S.K; Sharma, P. S. (1981). Thermal infrared and X-ray diffraction of manganese and zinc soaps, Asian J. Chem. 9: 388 - 394.

Wikipedia (2014) Coconut palm, wikipedia, the free encyclopedia, http://www.britannica.com/../coconut-palm

World Health Organization (WHO 2011). Guidelines for drinking water quality, $4^{\text {th }}$ Edition, Geneva, Switzerland, pp 564. 